\title{
PROVITAMIN A BIOFORTIFICATION IN MAIZE THROUGH GENETIC ENGINEERING AND MARKER-ASSISTED SELECTION
}

\author{
Nguyen Duc Thanh \\ Institute of Biotechnology, VAST, Vietnam \\ Received 6 May 2019, accepted 16 November 2019
}

\begin{abstract}
Maize is an important cereal in the global economy, which feeds one-third of the world's population and is the third largest food crop after wheat and rice. Nutritional quality of most maize varieties is very low due to the lack of lysine and tryptophan and extremely low provitamin A carotenoids including $\alpha$-carotene, $\beta$-carotene, and $\beta$-cryptoxanthin. Therefore, one of the solutions to improve nutritional value in maize is to improve provitamin A carotenoids contents. Many efforts have been made to produce maize plants with enhanced provitamin A carotenoids, especially, $\beta$-carotene. This article aims to review the research towards provitamin A biofortification through genetic engineering and marker-assisted selection. The published results and our recent achievements open the window for the improvement of provitamin A carotenoids in maize as well as the issues that need the further investigation.
\end{abstract}

Keywords: Zea mays L, $\beta$-carotene, biofortification, genetic engineering, maize, markerassisted-selection, provitamin A.

Citation: Nguyen Duc Thanh, 2019. Provitamin a biofortification in maize through genetic engineering and markerassisted selection. Academia Journal of Biology, 41(4): 37-53. https://doi.org/10.15625/2615-9023/v41n4.13804.

*Corresponding author email: nguyenducthanh_pcg@ibt.ac.vn

(C2019 Vietnam Academy of Science and Technology (VAST) 


\section{INTRODUCTION}

Maize, Zea mays L., is an important cereal in the global economy, which feeds one-third of the world's population and is the third largest food crop after wheat and rice. Nutritional quality of most maize varieties is very low due to the lack of lysine and tryptophan and extremely low provitamin A carotenoids including $\alpha$ carotene, $\beta$-carotene, and $\beta$-cryptoxanthin (Kurilich and Juvik, 1999).

Humans and animals cannot synthesize vitamin A, so it is necessary to provide provitamin A carotenoids in the diet. Vitamin A deficiency (VAD) is a global health problem that causes 140 to 250 million people at risk for many health problems, which can lead to blindness and increased disease and mortality rates in preschool children (WHO, 2010).

Biofortification is a process of increasing the density of vitamins and minerals in a crop through plant breeding, transgenic techniques, or agronomic practices (Bouis and Saltzman, 2017). Many efforts have been made to produce maize plants with increased provitamin A carotenoids, especially, $\beta$-carotene (Wurtzel et al., 2012). Although many strategies including supplementation, dietary diversification, and commercial fortification of foods have been deployed to overcome VAD, biofortification through genetic engineering and marker-assisted selection promise to be an effective and sustainable approach. The important basis for these approaches is identification of the key genes regulating carotenoid biosynthesis pathways and a number of functional molecular markers for genes/alleles related to increase in the levels of carotenoids in plants. Some such genes have been identified (Harjes et al., 2008; Yan et al., 2010), applied for gene transfer (Aluru et al., 2008; Zhu et al.,2008; Farre et al., 2013; Zanga et al., 2016) and selecting maize lines having high content of provitamin A carotenoids (Muthusamy et al., 2014; Liu et al., 2015; Zunjare et al., 2018). In this article, I will review the recent advances in these two approaches toward biofortification of provitamin A carotenoids, especially, $\beta$-carotene in maize.

\section{The importance of provitamin a carotenoids}

Carotenoids are naturally found in plants. Carotenoids containing $\beta$-ionone rings are known as provitamin A carotenoids including $\beta$-carotene, $\beta$-cryptoxanthin and $\alpha$-carotene. Provitamin A carotenoids are precursors of vitamin A - an essential micronutrient for humans. Vitamin A is very important for eye health, protects against age-related macular degeneration (US National Institute of Health, 2016), regulates and improves immune system and protects against infections (Ross, 1998; Semba, 1994; Semba, 2009, Huang et al., 2018). Vitamin A is also involved in regulation of gene expression (Combs, 2008), and thus plays an important role in development of the embryo, tissue growth, and cell renewal. Vitamin A deficiency (VAD) is a global health problem that causes 140 to 250 million people at risk for many health problems, which can lead to blindness and increased disease and mortality rates in preschool children (WHO, 2010). In addition, VAD also reduces the immune system in children leading to an increased risk of death from infectious diseases.

Humans cannot synthesize vitamin A de novo, and therefore need to obtain it from dietary sources either as preformed vitamin A (retinol) from animal-based foods (liver, fish, egg and dairy), or as precursors of vitamin A from colored vegetables and fruits (carrots, papaya, butternut squash, red bell pepper, grapefruit) in the form of provitamin A carotenoids.

In the human body, provitamin A carotenoids can be converted into physiologically active vitamin A (retinol) catalyzing by $\beta$-carotenoid-15,15'dioxygenase. $\beta$-carotene can generate two molecules of vitamin A, while $\alpha$-carotene and $\beta$-cryptoxanthin can produce only one molecule of vitamin $A$ as they only have a single non-hydroxylated $\beta$-ring (Davis et al., 2008). The conversion efficiency of dietary $\beta$ carotene to retinol was reported to be in the 
range of 3.6-28:1 by weight, but this varies according to the body weight of the test subjects and other factors (Tang, 2010). In 2001, the United States Institute of Medicine revised the standard ratio for bioconversion of $\beta$-carotene to retinol to $12: 1$ by weight (United States Institute of Medicine, 2001). Since 2001, the US Institute of Medicine uses retinol activity equivalents (RAE) for the Dietary Reference Intakes $(1 \mu \mathrm{g} \mathrm{RAE}=2 \mu \mathrm{g}$ all-trans- $\beta$-carotene from supplements $=$ $12 \mu \mathrm{g}$ of all-trans- $\beta$-carotene from food $=$ $24 \mu \mathrm{g} \alpha$-carotene or $\beta$-cryptoxanthin from food). World Health Organization recommends estimated average requirements of 250 and 500 RE (Retinol Equivalents) per day for children and adults respectively, for their normal growth and development (Bouis, Welch, 2010). RE was developed in 1967 by the United Nations Food and Agriculture Organization and World Health Organization $(1 \mu \mathrm{g} \mathrm{RE}=1 \mu \mathrm{g}$ retinol $=6 \mu \mathrm{g}$ $\beta$-carotene $=12 \mu \mathrm{g} \quad \alpha$-carotene or $\beta$ cryptoxanthin).

\section{Carotenoids in maize}

Maize is the third most important food crop after wheat and rice, consumed by more than one billion people in sub-Saharan Africa, Latin America and parts of Asia and provitamin A content from 3,167 to $9,792 \mu \mathrm{g} / \mathrm{g}$ would be preferred. In Vietnam, maize is the second largest food crop after rice. The concentration of provitamin A carotenoids, including $\beta$-carotene in maize kernels is very low. According to Harjes et al. (2008), most yellow maize grown and consumed throughout the world has only 0.5 to $1.5 \mu \mathrm{g} / \mathrm{g} \beta$-carotene. Kurilich and Juvik (1999) used HPLC to analyze carotenoids in five sweet maize lines and found that $\beta$ carotene contents ranged from 0.14 to 7.97 $\mu \mathrm{g} / \mathrm{g}$ dry weight (DW). The results from carotenoid concentration analysis of 36 yellow maize genotypes showed 13-ciscarotene contents ranging from 0.48 to 8.32 $\mu \mathrm{g} / \mathrm{g}$, trans- $\beta$-carotene 0.05 to $16,79 \mu \mathrm{g} / \mathrm{g}$ and 9-cis-carotene from 0.3 to $4.06 \mu \mathrm{g} / \mathrm{g}$ (Muzhingi et al., 2008). Vignes et al. (2012) analyzed $\beta$-carotene contents of 105 hybrid maize varieties in India - and CIMMYT (International Maize and Wheat Improvement Center) found a significant variation from 0.02 to $16.50 \mu \mathrm{g} / \mathrm{g}$ (Vignes et al., 2012). Thirusendura Selvi et al. (2014) analyzed the $\beta$-carotene contents of 24 lines of maize and showed a range from 0.23 to $7.92 \mu \mathrm{g} / \mathrm{g}$. Muthusamy et al. (2015) reported the significant difference in carotenoid contents in 105 native (India) and exotic tropical (CIMMYT) maize lines, namely; lutein (0.2$11.3 \mu \mathrm{g} / \mathrm{g})$, zeaxanthin $(0.2-20.0 \mu \mathrm{g} / \mathrm{g})$ and $\beta$ carotene $(0.0-15.0 \mu \mathrm{g} / \mathrm{g})$. At the same time, the authors found that environmental factors have little effect on the variation in carotenoid content and that genetic factors are important for the high carotenoid content. In the genetic study of carotenoids for improvement of provitamin A in adapted tropical maize varieties, Halilu et al. (2016) determined the content of $\beta$-carotene and provitamin $\mathrm{A}$ in 31 lines of adapted tropical yellow maize that have medium to high contents; for $\beta$-carotene, the content ranged from 1,867 to $8,277 \mu \mathrm{g} / \mathrm{g}$ and provitamin A content from 3,167 to $9,792 \mu \mathrm{g} / \mathrm{g}$.

Thus, for normal maize varieties, the carotenoid contents are not high. Therefore, the improvement of carotenoid content is highly desired. And therefore maize is considered an important candidate for improving metabolites in order to increase levels of zeaxanthin, lutein, and provitamin A in food crops (Messias et al., 2014). Moreover, maize is closely related to some other food crops in the Poaceae family, so that it may also be possible to use the methods for improving provitamin $\mathrm{A}$ in maize for other cereal species (Wurtzel et al., 2012).

Genetic improvement of staple crops for improved nutritional quality (enhanced level of micronutrients and provitamin A) is termed biofortification and is a promising approach for reducing vitamin $\mathrm{A}$ and other micronutrient deficiencies in humans. The biofortification of maize with higher levels of provitamin A carotenoids can play a significant role in reducing vitamin A deficiency in regions where maize is a major staple crop (Wurtzel et 
al. 2012; Burt et al. 2011; Meyers et al. 2014). The HarvestPlus, a biofortification program initiated by CIMMYT, has set the target level of $15 \mu \mathrm{g} / \mathrm{g} \beta$-carotene to reduce vitamin A deficiency, considering the loss of 50\% after post-harvest and cooking, and bioconversion rate of 12:1 of provitamin A into retinol. Thus, daily maize consumption of 200 and $400 \mathrm{~g}$ could meet daily requirement for children and women, respectively (Ortiz-Monasterio et al., 2007).

\section{Carotenoid biosynthesis and accummulation}

Carotenoid biosynthesis pathway (Fig. 1) initiates with the synthesis of geranylgeranyl diphosphate (GGPP), a C20 intermediate and this reaction is catalyzed by GGPP synthase (GGPPS) enzyme. Two molecules of GGPP are condensed into 15-cis-phytoene mediated by phytoene synthase (PSY) enzyme. Later on, a series of desaturation reactions are carried out by phytoene desaturase (PDS), $\zeta$-carotene desaturase $(Z D S)$ and two isomerases (Z-ISO, $\zeta$-carotene isomerase; CRTISO, carotenoid isomerase) result in a series of double bonds and alter the isomer state of each biosynthetic intermediate to produce all-trans-lycopene (Chen et al., 2010, Wurtzel et al., 2012). At this step, depending on cyclization activity, two branches of pathways occur as lycopene acts as substrate for two competing enzymes, lycopene $\beta$-cyclase $(L Y C B)$ and lycopene $\beta$ cyclase ( $L Y C E)$. Asymmetric cyclization of lycopene by both $\varepsilon$ - and $\beta$-lycopene cyclase, respectively, produces $\alpha$-carotene with one $\varepsilon$ and one $\beta$-ionone ring. Symmetric cyclization by $\angle C Y B$ results in $\beta$-carotene, with two unmodified $\beta$-ionone rings (Wurtzel et al., 2012). In the presence of $\beta$-carotene hydroxylase $(B C H)$ enzyme, $\alpha$-carotene is converted into lutein, whereas $\beta$-carotene is converted into zeaxanthin. Prior to zeaxanthin formation, an intermediate $\beta$-cryptoxanthin is also produced but it is quickly converted into abscisic acid through the xanthophyll cycle (Seo, Koshiba, 2002). Lutein is the end product of $\alpha$-carotene branch.

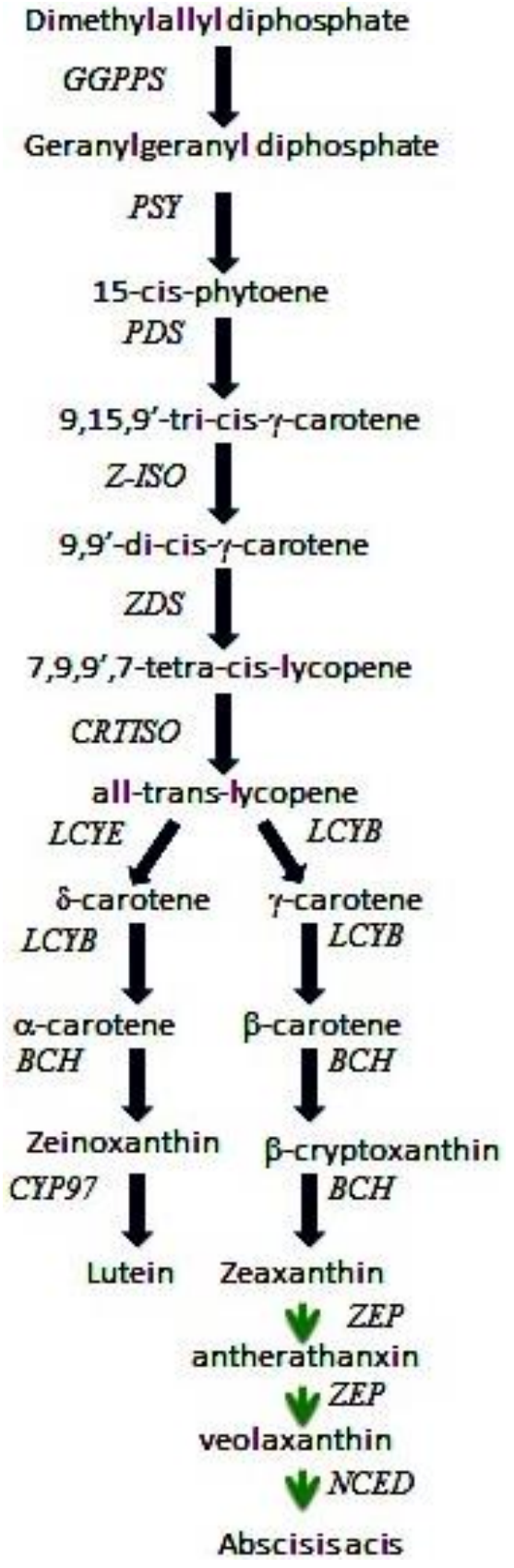

Figure 1. Simplified carotenoid biosynthesis pathways: GGPP: Geranylgeranyl diphosphate; PSY: Phytoene synthase; PDS: Phytoene desaturase; ZDS: $\zeta$-carotene desaturase; CRTISO: carotene isomerase; LCYB: Lycopene beta cyclase; LCYE: Lycopene epsilon cyclase; $\mathrm{BCH}$ : $\beta$-carotene hydroxylase; ZEP: Zeaxanthin epoxidase; NCED: 9-cis-epoxycarotenoid dioxygenase 
It is clear that the pathways include several physiological events from initiation with geranylgeranyl diphosphate (GGPP) to the last step at abscisic acid or lutein. By understanding the critical steps in the pathway, we can modulate the pathway for enhancement of the desired products. In order to do that, the key genes regulating the pathway should be identified and modulated to increase the biosynthesis of provitamin $\mathrm{A}$ carotenoids. As in figure 1, the key genes are the genes coding for phytoene synthase (PSY), phytoene desaturase $(P D S), \quad \zeta$-carotene desaturase $(Z D S)$, lycopene $\beta$-cyclase $(L C Y B)$, lycopene $\varepsilon$-cyclase $(L C Y E)$ and $\beta$-carotene hydroxylase 1 (crtRBI). However, all of these genes are not equally effective in the production of provitamin A carotenoids. So far PSY1 gene is known to play a critical role in formation of phytoene by condensation of two molecules of geranylgeranyl pyrophosphate (GGPP). Earlier, PSY1 was known as $Y 1$ gene that determines the variability in the kernel color ranging from white to orange (Buckner et al., 1990, Buckner et al., 1996). The role of PSYI was validated by transgenic overexpression of this gene in white kernels which produced transgenic plants with yellow grains (Zhu et al., 2008). PSY1 gene has two polymorphic sites; a 378-bp InDel is located upstream of the transcription start site and a SNP on fifth exon, and both of these polymorphs account for $7 \%$ and $8 \%$ of the total carotenoid variance, respectively. PDS (phytoene desaturase) and $\zeta$-carotene desaturase (ZDS) genes regulate the desaturation of phytoene to produce lycopene - the first colored pigment to be produced in the pathways ( $\mathrm{Li}$ et al., 1996). Two enzymes lycopene $\beta$-cyclase $(L C Y B)$ and lycopene $\varepsilon$-cyclase $(L C Y E)$ react with lycopene to generate $\beta$-carotene and $\alpha$ carotene. Harjes et al. (2008) described that the progression for $\beta$-carotene branch was increased over $\alpha$-carotene by down-regulating the $L C Y E$ gene. $\beta$-carotene hydroxylase 1 $(B C H / c r t R B 1)$ is involved in hydroxylation of $\alpha$-carotene and $\beta$-carotene producing nonprovitamin A carotenoids lutein and zeaxanthin, respectively. crtRB1 is also known as HYD3 (Hydroxylase 3), however, hydroxylation of carotenes increases the proportion of xanthophylls having no provitamin A activity (Matthews, Wurtzel, 2007). HYD3 encodes one of the carotene hydroxylases. Transcripts of HYD3 were positively correlated with zeaxanthin and negatively associated with $\beta$-carotene levels. HYD 3 accounted for $36 \%$ of the phenotypic variance for $\beta$-carotene concentration (Vallabhaneni, Wurtzel, 2009).

Carotenoids in plants are synthesized in the membranes of plastids and stocked in chromoplasts of flowers, fruits and roots (Howitt, Pogson, 2006). Chromoplast has a special mechanism for storing large amounts of carotenoids by creating structures called carotenoid-lipoprotein structures inside the chromoplast. These structures are also known as carotenoid isolation structures. The isolation structures act as reservoirs to store/isolate carotenoids and prevent the end product of carotenoid synthesis from affecting the synthesis of carotenoids in chromoplast membranes (Al Babili et al., 1999). In chromoplasts, carotenoids accumulate often in esterified form. The esterification enhances carotenoid stability. While, in chloroplasts, carotenoids associate with chlorophylls and pigment binding proteins giving the proper function of the photosynthetic apparatus. The binding of carotenoids with different classes of pigment binding proteins in chromoplasts (Vishnevetsky et al., 1999) and chloroplasts (Neilson, Durnford, 2010) contributes to the stability of carotenoids.

Once the potential genes such as PSYI, $P D S, Z D S, L C Y B, L C Y E$ and $c r t R B 1$ involved in the biosynthesis of provitamin $A$ carotenoids are recognized, we can employ them for provitamin A biofortification in maize either by genetic engineering or marker-assisted selection. For the latter, the molecular markers associated with these genes need to be identified to precisely exploit them for provitamin A biofortification. The role of other genes in the synthesis pathway and accumulation of provitamin A carotenoids 
can be explored for faster and more effective provitamin A biofortification in maize.

\section{Strategies for improvement of carotenoid content}

Based on the knowledge of biosynthesis and accumulation, improving the carotenoid levels in plants can be done with the interference of carotenoid biosynthesis cycle by enhancing the expression of genes that encode key enzymes involved in synthesis, or inhibition of certain genes that encode substances that degrade carotenoids, and the use of genes regulating carotenoid accumulation.

Enhancing the expression of one or more genes that encode key enzymes involved in synthesis of carotenoids is the first strategy. This had been done in rice (Ye et al., 2000), potato (Diretto et al., 2007), cassava (Wesch et al., 2010), wheat (Wang et al., 2014), and bananas (Paul et al., 2017). In maize, Zhu et al (2008) transformed different combinations of 5 carotenogenic genes controlled by different endosperm-specific promoters into a white maize variety and generated transgenic plants expressing different enzyme combinations and showing different carotenoid compositions. However, overexpression of synthetic enzymes may lead to the depletion of synthetic precursors, thus limiting the accumulation of the desired product.

Expression of enzymes that inhibit certain genes encoding for substances that degrade carotenoids is the second strategy for the improvement of carotenoids content. Romer et al (2002) have generated transgenic potato with elevated zeaxanthin content 4 to 130 fold by antisense inactivation and co-suppression of carotenoid epoxidation. Using a similar approach, ZEP (Diretto et al., 2006) and LCYE (Pons et al., 2014) genes were silenced to improve zeaxanthin and $\beta$-carotene, respectively. Alternative strategy is the combination of enhancing and inhibiting gene expression as shown by overexpression $\operatorname{crtB}$ gene combined with silencing of carotenoid hydroxylase gene $(\mathrm{CHY})$ in wheat that resulted the increase of $\beta$-carotene up to 31 fold (Zheng et al., 2015). In maize, transgenic plants with high value carotenoid astaxanthin in the kernel endosperm were produced by combining the overexpression of PSY gene for enhanced carotenoid production and silencing of $L C Y E$ gene for directing more precursors into the $\beta$-branch (Farre et al., 2016).

The third strategy is the use of gene regulating carotenoid accumulation. This strategy was employed first by Lu's and Lopez's work, showing that the mutated Brassica oleracea Or gene (BoORMUT) showed its effect by triggering chromoplast differentiation and enhancing storage sink strength for carotenoid biosynthesis and accumulation (Lu et al., 2006; Lopez et al., 2008). The overexpression of wild-type $\mathrm{Or}$ gene also enhanced the carotenoid accumulation in sweet potato (Kim et al., 2013) and in the calli of rice (Bai et al., 2014). The carotenoid accumulation driven by the $\mathrm{Or}$ gene associated with the differentiation of non-pigmented plastids into chromoplasts and the formation of the metabolic sinks (Lu et al., 2006, Zhou et al., 2008). The Or gene codes for plastid protein containing a DnaJ Cys-rich domain that is associated with high carotenoid accumulation. In addition to the role in carotenoid accumulation, a recent study showed that the Or protein of Arabidopsis thaliana interacts directly with PSY protein and functions as a major regulator of active PSY protein abundance in mediating carotenoid biosynthesis (Zhou et al., 2015). The overexpression of the $O r$ gene from Ipomea batatas (IbOr) in transgenic plants of sweetpotato, potato and alfalfa (Park et al., 2015; Cho et al., 2016; Li et al., 2012; Guo et al., 2015; Wang et al., 2015) has led to increased carotenoid accumulation without affecting carotenoid synthesis. A recent report on the role of Arabidopsis thaliana Or gene (AtOr, Berman et al., 2017) and sweet potato Or gene (IbOr, Tran et al., 2017) in maize suggested the potential use of $\mathrm{Or}$ gene to improve the carotenoid accumulation in staple crops including maize. In our recent work, the $\mathrm{IbOr}$ gene isolated form local sweet potato cultivar Hoang Long (Ipomea batatas cv. 
Hoang Long) and placed under the control of maize seed-specific promoter globulin 1 (Glo1), has been successfully transferred into inbred maize lines and total carotenoid and $\beta$ carotene content of generated transgenic plants were significantly higher than those of wildtype and in the best line, the total carotenoid and $\beta$-carotene content were increased up to 10.36 and 15.11 fold, respectively (Tran et al., 2017). To our best knowledge, our research is the first to successfully overexpress the $\mathrm{IbOr}$ gene in maize.

Marker-assisted selection (MAS), particularly marker-assisted back crossing and introgression (MABC, MASI) are the fourth strategy for the improvement of carotenoid contents. This strategy is realized on the natural variation of carotenoid content and DNA marker associated with the genes/QTLs or alleles that are crucial for carotenoid synthesis and accumulation.

There is a wide range of levels of provitamin A carotenoids in temperate, tropical and subtropical germplasm (Ortiz-Monasterio et al. 2007; Menkir et al. 2008). Tropical maize contains less $\beta$-carotene than temperate maize, so the initial breeding sources of high provitamin A carotenoids can be selected from temperate maize (Pixley et al. 2013; Menkir et al. 2017). However, evaluation of a wider range of tropical germplasm in future may identify potential donors for enhanced $\beta$ carotene content. Babu et al. (2013) reported the range to be $15-20 \mu \mathrm{g} / \mathrm{g}$ provitamin A contents in improved inbred lines, whereas Suwarno et al. (2015) reported 2.34-22.25 $\mu \mathrm{g} / \mathrm{g}$ provitamin A contents in maize kernels. Breeding lines of maize that can accumulate up to $26 \mu \mathrm{g} / \mathrm{g} \quad \beta$-carotene (and $30 \mu \mathrm{g} / \mathrm{g}$ of provitamin A carotenoids) in the endosperm have been reported (Pixley et al. 2013). The maize lines having high provitamin A carotenoids content can be used as the provitamin A donors for the improvement of provitamin A carotenoids in maize.

Results of the studies on the role of the crtRBI and LCYE genes in the accumulation of $\beta$-carotene in maize (Harjes et al., 2008;
Yan et al., 2010; Babu et al., 2013; Zhang et al., 2012; Azmach et al., 2013) showed different roles of different alleles of these two genes on $\beta$-carotene content in maize kernels. Harjes et al. (2008) suggested that the reduced functionality of $L C Y E$ gene shifts more lycopene into the $\beta$-branch of the pathway, thereby enhancing the flux towards provitamin A carotenoids. The authors reported the presence of four alleles in the 5'TE region of the $L C Y E$ gene, including allele $1(150+280 \mathrm{bp})$, allele $2(250 \mathrm{bp})$, allele $3(250 \mathrm{bp}+380 \mathrm{bp})$ and allele 4 (650 bp). Of these, allele 1 and allele 4 are two regulating alleles that increase the provitamin A carotenoids through the $\beta$-branch, and these alleles are known as favorable alleles. While allele 2 and allele 3 are unfavorable alleles as they negatively affect the provitamin A levels in maize kernels. There were two alleles in the 3'TE region of the $L C Y E$ gene: allele $1(399+$ 502 bp) and allele 2 with 8 bp deletion ( $144+$ $502 \mathrm{bp}$ ), and allele 2 is the favorable allele (Harjes et al., 2008).

crtRB1 gene is involved in conversion of $\beta$-carotene into $\beta$-cryptoxanthin which has only a half of provitamin A activity compared to $\beta$-carotene. Yan et al. (2010) have discovered the natural genetic variation of $c r t R B 1$ that reduced functionality of $\operatorname{crtRBI}$ gene leading to increased accumulation of $\beta$ carotene in the maize endosperm. Through linkage mapping, three regions of the crtRBI gene have been identified that are significantly associated with the changes in $\beta$ carotene levels: The 5'TE end (in non-coding region), InDel4 (in the coding region) and the 3'TE end (extends from the 6th exon and the untranslated 3'-region). crtRB1 3'TE polymorphism produces three alleles: allele 1 (543 bp without insertion), allele 2 (296 bp + $875 \mathrm{bp}$, with insertion of $325 \mathrm{bp}$ ) and allele 3 $(296 \mathrm{bp}+1221 \mathrm{bp}+1880 \mathrm{bp}$, with insertion of $1,250 \mathrm{bp}$ ) associated with $\beta$-carotene accumulation (Yan et al., 2010). Allele 1 is known as an allele favorable for increasing $\beta$ carotene by reducing the transcriptional expression of the $c r t R B 1$ gene, whereas allele 2 and allele 3 are unfavorable alleles. crtRB1 
5'TE polymorphism also produces three alleles: allele 1 with 397-bp insertion, allele 2 with 206-bp insertion, and allele 3 without insertion. Among these, alleles $2(600+206$ $\mathrm{bp}$ ) is the favorable.

DNA markers associated with favorable alleles of crtRBI and LCYE genes were identified, validated and used in markerassisted selection and introgression in temperate and tropical maize (Babu et al., 2013). Azmach et al (2013) had analyzed the association of functional gene markers for provitamin A levels across diverse tropical yellow maize inbred lines and revealed tropical maize inbred lines harboring the favorable alleles of the crtRB1-5'TE and crtRB1-3'TE functional markers produce higher levels of provitamin A. Such maize lines can be used as donor parents to cross with elite germplasm of maize that had high yield potential and good agronomic traits, such as disease resistance and drought tolerance. However, the challenge for markerassisted selection of high provitamin A carotenoids is the low frequency of favorable alleles in traditional maize population. Muthusamy et al., (2015b) has screened a diverse set of 385 maize inbred lines of indigenous and exotic origin and detected the presence of two alleles (amplicon size: 250 and $650 \mathrm{bp)}$ of LCYE and three alleles (amplicon size: 296, 543 and 875 bp) of crtRBI in the inbred panel. Favorable alleles of both genes were rare among the traditional maize germplasm; $3.38 \%$ of the inbred possessed the favorable allele $(650 \mathrm{bp})$ of $\angle C Y E$, and $3.9 \%$ inbred had the favorable allele (543 bp) of crtRB1. Five inbred (1.3\%) with favorable alleles of both genes were found. Inbred with favorable alleles of $\operatorname{crtRBI}$ and $L C Y E$ serves as rich genetic resources for effective utilization in the maize biofortifcation program.

Improvement of provitamin a carotenoid content in maize through genetic engineering

Although the improvement of provitamin A carotenoids content in crops can be done by conventional breeding, this method relies on the existing gene pool so it must take long time to develop a new variety. In maize, the gene pool for high provitamin A content is very limited. Therefore, enhancing provitamin A carotenoids in maize will be more effective by using genetic engineering including overexpression of genes that encode key enzymes involved in synthesis of carotenoids, or inhibition of certain genes that encode substances that degrade carotenoids, and the use of the genes regulating carotenoid accumulation through transgenic approaches.

Improvement of provitamin A carotenoid content in maize through transgenic approaches has started with the production of transgenic maize plants by introducing the bacterial $C R T B$ and $C R T I$ genes under the control of super $\gamma$-seen promoters resulting in an increase of total carotenoids of up to 34fold with a preferential accumulation of $\beta$ carotene in the maize endosperm (Aluru et al., 2008). At the same time, Zhu et al. (2008) transformed the five carotenoid genes including Zmpsyl (Zea mays phytoene synthase 1), PacrtI (Pantoea ananatis phytoene desaturase), Gllycb (Gentiana lutea lycopene-cyclase), Glbch (G. lutea -carotene hydroxylase), and ParacrtW (Paracoccuscarotene ketolase) under the control of endosperm-specific promoters and generated transgenic maize plants with extraordinary levels of $\beta$-carotene $(57.35 \mu \mathrm{g} / \mathrm{g} \mathrm{DW})$ and other carotenoids, including complex mixtures of hydroxycarotenoids and ketocarotenoids. Naqvi et al. (2009) simultaneously transferred maize ZmPSY1 cDNA under the control of wheat LMW glutenin promoter along with CRTI gene from Pantoea ananatis under the control of barley Dhordein promoter, dhar gene from rice (for ascorbate) and E. coli folE gene (for folate) to maize. They were able to produce a transgenic line containing 169 -fold higher the normal amount of $\beta$-carotene, 6fold the normal amount of ascorbate, and double the normal amount of folate.

Genetic engineering of maize for improvement of provitamin A carotenoid also can be done by boosting $\beta$-carotene 
production and reduce $\alpha$-carotene production or by the inhibition of genes that encode substances that degrade provitamin A carotenoids. Ferre et al. (2016) introduced $P S Y$ and $L C Y E$ into a white maize genetic background to extend the carotenoid pathway to astaxanthin. Simultaneously, phytoene synthase, the controlling enzyme of carotenogenesis, was overexpressed for enhanced carotenoid production and lycopene $\varepsilon$-cyclase was knocked-down to direct more precursors into the $\beta$-branch of the extended ketocarotenoid pathway to form astaxanthin. High-carotenoid maize (Carolight) was developed by introducing the $P S Y 1$ gene from maize and CRT1 gene from Pantoea annatis in the genetic background of $\mathrm{M} 37 \mathrm{~W}$, a white endosperm maize variety. Total carotenoid contents were comparable under greenhouse conditions; and field studies showed the mean of approximate $106 \pm 7 \mu \mathrm{g} / \mathrm{g}$ which was significantly higher than $86 \pm 0.65 \mu \mathrm{g} / \mathrm{g}$ as reported in another study on $\mathrm{T} 1$ generation of Carolight line (Farre et al., 2013; Zanga et al., 2016).

The use of the genes regulating carotenoid accumulation was started with the works of $\mathrm{Lu}$ et al. (2006) introducing the Or gene isolated from an orange cauliflower (Brassica oleracea var. botrytis) mutant that confers high level accumulation of $\beta$-carotene in tissues that normally lack this pigment into potato (Solanum tuberosum L. cv. Desiree) and transgenic tubers have thus been produced with 6-fold increased levels of total carotenoids. The results demonstrated that the Or gene can serve as a new molecular tool to manipulate carotenoid content and composition in food crops. In maize, recently, Berman et al. (2017) have overexpressed the Arabidopsis OR gene (AtOR) under the control of the endosperm-specific wheat LMW glutenin promoter in a white maize variety $\mathrm{M} 37 \mathrm{~W}$ that normally accumulates only trace amounts of carotenoids. The total endosperm carotenoid content in the bestperforming AtOR transgenic maize line was 32-fold higher than wild-type controls (25 $\mu \mathrm{g} / \mathrm{g}$ DW) and the other principal carotenoids remained the same. Recently, we have successfully produced transgenic maize plants with considerably increased total carotenoids and $\beta$-carotene (Tran et al., 2017). The $\mathrm{Or}$ gene cloned from yellow-fleshed sweet potato cultivar Hoang Long (named $\mathrm{IbOr}$ gene) was transferred into two inbred maize lines (H145 and H95) through A. tumefaciens under the control of maize seed-specific promoter globulin 1 (Glo1). In the best transgenic line (H145-IbOr.10), the total carotenoids and $\beta$ carotene content were increased up to 10.36 $(27.6 \mu \mathrm{g} / \mathrm{g} \mathrm{DW})$ and $15.11(19.35 \mu \mathrm{g} / \mathrm{g}$ DW $)$ fold, comparing to wild-type (2.67 and 1.28 $\mu \mathrm{g} / \mathrm{g}$ DW), respectively (Tran et al., 2017). These results indicate the potential use of the Or gene to improve the carotenoid content in maize and other staple crops.

\section{Improvement of provitamin a carotenoid content in maize through marker-assisted selection}

Although genetic engineering is a potential tool for provitamin A carotenoid enrichment in food crops, the biosafety, public perception and other related regulatory issues must be considered prior to generalizing transgenic crops for public consumption. These are the important challenges for the application of genetic engineering in provitamin A biofortification in maize and other crops. Much progress has been made towards elucidating the genes that regulate carotenoid biosynthesis in maize endosperm and several functional markers associated with genes/alleles related to the enrichment of provitamin A content in maize have been identified. This provides a basis for utilization of marker-assisted selection of high provitamin A carotenoids in maize.

Recent findings demonstrated that downstream genes, particularly $L C Y E$ and crtRB 1, from carotenoid biosynthesis pathway play a major role in accumulation of provitamin A carotenoids in maize endosperm (Harjes et al., 2008; Yan et al., 2010). Harjes et al. (2008) suggested that the reduced functionality of $L C Y E$ shifts more lycopene into the $\beta$-branch of the pathway, thereby 
enhancing the flux towards provitamin A carotenoids. Besides $L C Y E$, favorable alleles of $\operatorname{crtRBl}$ were also reported to increase $\beta$ carotene content in maize kernel (Yan et al., 2010). Favorable alleles for provitamin A contents were initially identified in temperate maize germplasm which are now being introgressed into tropical maize germplasm. DNA markers associated with favorable alleles were identified, validated and being used in a wide range of maize germplasm (Babu et al., 2013). The potential of the crtRB1-specific markers for enrichment of provitamin A carotenoids in maize grain has been used for marker-assisted backcrossing in quality protein maize (QPM) inbred and hybrids (Muthusamy et al., 2014; Liu et al., 2015). Muthusamy et al. (2014) successfully introgressed the favorable alleles (543 bp) of crtRBl gene in elite maize genotypes through marker-assisted backcross breeding. crtRB1specific markers were used for foreground selection, and $90 \%$ of the recurrent parent genome was restored within two backcross generations. $\beta$-carotene among the crtRB1introgressed inbred varied from 8.6 to 17.5 $\mu \mathrm{g} / \mathrm{g}$ - a maximum increase up to 12.6 -fold over recurrent parent. Marker-assisted stacking of crtRB1, LCYE and $o 2$ genes was undertaken in the genetic background of four maize hybrids (HQPM1, HQPM4, HQPM5, and HQPM7) popularly grown in India. HP704-22 and HP704-23 were used as donors, while four elite QPM parents HKI161, HKI163, HKI193-1 and HKI193-2 were used as recipients. Recovery of recurrent parent genome (RPG) among selected backcross progenies ranged from 89 to $93 \%$. Introgressed progenies possessed high concentration of provitamin A (7.38-13.59 $\mu \mathrm{g} / \mathrm{g}$ ), compared to $1.65-2.04 \mu \mathrm{g} / \mathrm{g}$ in the recurrent parents (Zunjare et al., 2018). Goswami et al. (2019) reported marker-assisted introgression of rare allele of $\beta$-carotene hydroxylase (crtRBI) gene into elite quality protein maize inbred for combining high lysine, tryptophan and provitamin A in maize. The results showed that introgressed lines possessed higher mean $\beta$-carotene $(9.22 \mu \mathrm{g} / \mathrm{g}), \beta$-cryptoxanthin (3.05 $\mu \mathrm{g} / \mathrm{g})$ and provitamin A $(10.75 \mu \mathrm{g} / \mathrm{g})$ compared to the recipient line HKI1128Q $(2.26 \mu \mathrm{g} / \mathrm{g}, \quad 2.26 \mu \mathrm{g} / \mathrm{g}$ and $3.38 \mu \mathrm{g} / \mathrm{g}$, respectively). Moreover, high concentration of essential amino acids such as lysine $(0.303 \%)$ and tryptophan $(0.080 \%)$ in endosperm was also recorded. In the other similar work, Sagare et al. (2019) had carried out the marker-assisted backcrossing using $\beta$-carotene donor MGU23379 $(6.31 \mu \mathrm{g} / \mathrm{g}$ of $\beta$-carotene $)$ to cross with high quality protein recurrent parents, CB6-36 (CBML6) and CB7-28 (CBML7). Foreground selection was carried out with crtRB1-3'TE and umc1066 markers. Tryptophan/lysine content in introgressed progenies was retained as in the recurrent parents, but $\beta$-carotene content was significantly high $(6.25$ and $6.80 \mu \mathrm{g} / \mathrm{g})$ compared to the original inbred line $(0.71$ and $1.29 \mu \mathrm{g} / \mathrm{g})$.

Provitamin A biofortification of maize with the target of improving $\beta$-carotene concentration in maize grain beyond $15 \mu \mathrm{g} / \mathrm{g}$ to provide an additional $50 \%$ of the estimated average requirement for Vitamin A in maizeeating regions (Menkir et al., 2018) was started by the HarvestPlus-Maize Program at CIMMYT and considerable progress has been achieved to date. With the discovery of useful allelic diversity for $L C Y E$ and crtRBI and development of molecular markers, source lines with $>15 \mu \mathrm{g} / \mathrm{g}$ of provitamin A carotenoids have been identified and are now routinely used as parents for new crosses at CIMMYT. This has led to the selection of lines with 40-250\% higher provitamin A carotenoid concentrations than lines without the favorable allele (Babu et al., 2013).

\section{The challenges and solutions in the future}

Although many impressible achievements have been made in biofortification of carotenoids and provitamin A carotenoids in several crops including maize through genetic engineering, major challenges for biofortified transgenic crops are bio-safety and the lengthy regulatory process needed before they get released for cultivation and consumption. Due to this, none of the genetically biofortified 
crops have been released for cultivation or consumption (De Steur et al., 2017). The development of new technologies such as gene editing to knock-out mutations blocking $\beta$-carotene hydroxylation, or lycopene $\beta$ cyclization, which are able to increase $\beta$ carotene content (Belhaj et al., 2013) or make point mutations able to increase $\beta$-carotene content, like the mutations Arg $>$ His in $O R$ gene (Tzuri et al., 2015) or Ala > Asp in PSY gene (Welsch et al., 2010) could be a potential solution for the future of provitamin A biofortification in maize. Gene editing tools may have wider public acceptability than genetic engineering technologies as they are closer to natural processes. Hence, gene editing may have a huge potential for genetic improvement of crop plants in general, and thus, this technology could be exploited in future for modifying the carotenoid biosynthesis pathway in maize for improvement of provitamin A carotenoids.

One of the challenges for marker-assisted selection (MAS) in provitamin A biofortification in maize, especially tropical maize is the limited high $\beta$-carotene resources. However, this can be overcome by the use of temperate or transgenic improved resources for backcrossing. The other challenge is that there are still very few favorable alleles of PSY1, LcyE and crtRBIgenes that have been identified and manipulated in maize using MAS for enrichment of provitamin A. Moreover, such alleles are rare even in temperate maize. Therefore, association mapping and whole genome sequence analyses approaches could be used for rapid generation of selectable markers in diverse germplasm, and can enable breeders to find the favorable alleles in their locally adapted germplasm sources (Harjes et al 2008). In addition, the studies on identification of favorable alleles for other functional genes in the carotenoid biosynthetic pathways which increase the synthesis of total carotenoids and enhance the accumulation of $\beta$-carotene need to be carried out.

\section{CONCLUSION}

The application of genetic engineering and marker-assisted selection for provitamin A biofortification in maize has gained remarkable achievements. By gene technology, maize lines with hundreds fold higher $\beta$-carotene content compared to control have been produced. With marker-assisted selection, maize lines with $\beta$-carotene above the recommended level of $15 \mu \mathrm{g} / \mathrm{mg}$ dry weight and meeting $50 \%$ of vitamin A requirement for humans have also been reported. However, the release of provitamin A fortified transgenic plants is a long process. Marker-assisted selection (MAS) and MarkerAssisted Backcross Breeding (MABB) are viable approaches to develop provitamin $\mathrm{A}$ biofortified maize. However, due to the lack of natural genetic resources with high levels of $\beta$-carotene that can be used as donor materials and the number of potential functional genes and molecular markers associated with these genes being limited, MAS is still not fully effective. With the development of environmental friendly gene technology (use of plant-derived genes and antibiotic-free selection), gene editing and mutation producing by gene editing tools like Zinc Finger Nucleases (ZFNs), Transcription Activator-Like Effector Nucleases (TALENs), Clustered Regularly Interspaced Short Palindromic Repeats/Cas (CRISPR/Cas), or applying whole genome sequencing and Genome Wide Association Study (GWAS) for rapid identification of functional genes and generation of selectable markers for MAS, the provitamin A biofortification in maize and other staple crops will be more accurate, fast and efficient.

Acknowledgments: The work was implemented under the Program of Supporting scientific research activities for senior researchers 2019 from Vietnam Academy of Science and Technology, Code: NCVCC08.05 / 19-19.

\section{REFERENCES}

Al Babili S., Hartung W., Kleinig H., Beyer P., 1999. CPTA modulates levels of 
carotenogenic proteins and their mRNAs and affects carotenoid and $\mathrm{ABA}$ content as well as chromoplast structure in Narcissus pseudonarcissus flowers. Plant Biol., 1: 607-612.

Aluru M., Xu Y., Guo R., Wang Z., Li S., White W., Wang K., Rodermel S., 2008. Generation of transgenic maize with enhanced pro-vitamin A content. J. Exp. Bot., 59: 3551-3562.

Babu R, Rojas N. P., Gao S., Yan J., Pixley K., 2012. Validation of the effects of molecular marker polymorphisms in LCYE and CrtRB1 on provitamin A concentrations for 26 tropical maize populations. Theor. Appl. Genet., 126(2): 389-399.

Bai C., Rivera S., Medina V., Alves R., Vilaprinio E., Sorribas A., Canela R., Capell T., Sandmann G., Christou P., Zhu C., 2014. An in vitro system for the rapid functional characterization of genes involved in carotenoid biosynthesis and accumulation. Plant J., 77(3): 464-475.

Belhaj K., Chaparro-Garcia A., Kamoun S., Nekrasov V., 2013. Plant genome editing made easy: targeted mutagenesis in model and crop plants using the crispr/cas system. Plant Methods 9: 39. https:// doi.org/10.1186/1746-4811-9-39.

Berman J., Zorrilla-López U., Medina V., Farré G., Sandmann G., Capell T., Christou P., Zhu C., 2017. The Arabidopsis ORANGE (AtOR) gene promotes carotenoid accumulation in transgenic maize hybrids derived from parental lines with limited carotenoid pools. Plant Cell Rep. https:// doi.org/ 10.1007/s00299-017-2126-z.

Bouis H. E., Welch R. M., 2010. Biofortification - a sustainable agricultural strategy for reducing micronutrient malnutrition in the global South. Crop Sci., 50: S20-S32.

Bouis H. E., Saltzman A., 2017. Improving nutrition through biofortification: A review of evidence from HarvestPlus,
2003 through 2016. Global Food Security, 12: 49-58.

Buckner B., Kelson T. L., Robertson D. S., 1990. Cloning of the y1 locus of maize, a gene involved in the biosynthesis of carotenoids. Plant Cell, 2: 867-876.

Buckner B., Miguel P. S., Janickbuckner D., Bennetzen J. L., 1996. The Y1 gene of maize codes for phytoene synthase. Genetics, 143: 479-488.

Burt A. J., Grainger C. M., Smid M. P., Shelp B. J., Lee E. A., 2011. Allele mining of exotic maize germplasm to enhance macular carotenoids. Crop Sci., 51: 9911004.

Chen Y., Li F., Wurtzel E. T., 2010. Isolation and characterization of the Z-ISO gene encoding a missing component of carotenoid biosynthesis in plants. Plant Physiol., 153: 66-79.

Cho K. S., Han E. H., Kwak S. S., Cho J. H., Im J. S., Hong S. Y., Sohn H. B., Kim Y. H., Lee S. W., 2016. Expressing the sweetpotato orange gene in transgenic potato improves drought tolerance and marketable tuber production. $C R$ Biol., 339: 207-213.

Combs G. F., 2008. The Vitamins: Fundamental Aspects in Nutrition and Health (3rd ed.). Burlington: Elsevier Academic Press.

Davis C., Jing H., Howe J. A., Rocheford T., Tanumihardjo S. A., 2008. $\beta$ Cryptoxanthin from supplements or carotenoid enhanced maize maintains liver vitamin A in Mongolian gerbils (Meriones unguiculatus) better than or equal to $\beta$ carotene supplements. Br. J. Nutr., 100: 1-8.

De Steur H., Mehta S., Gellynck X., Finkelstein J. L., 2017. GM biofortified crops: potential effects on targeting the micronutrient intake gap in human populations. Curr. Opin. Biotechnol., 44:181-188.

Diretto G., Al-Babili S., Tavazza R., Papacchioli V., Beyer P., Giuliano G., 
2007. Metabolic engineering of potato carotenoid content through tuber-specific overexpression of a bacterial minipathway. PLoS One, 2: e350

Diretto G., Tavazza R., Welsch R., Pizzichini D., Mourgues F., Papacchioli V., Beyer P., Giuliano G., 2006. Metabolic engineering of potato tuber carotenoids through tuber-specific silencing of lycopene epsilon cyclase. BMC Plant Biol., 6: 13.

Farre G., Rivera S. M., Alves R., Vilaprinyo E., Sorribas A., Canela R., Naqvi S., Sandmann G., Capell T., Zhu C., Christou P., 2013. Targeted transcriptomics and metabolic profiling reveals temporal bottlenecks in the maize carotenoid pathway that can be addressed by multigene engineering. Plant J., 75: 441-455.

Farre G., Perez-Fons L., Decourcelle M., Breitenbach J., Hem S., Zhu C., Capell T., Christou P., Fraser P.D., Sandmann G., 2016. Metabolic engineering of astaxanthin biosynthesis in maize endosperm and characterization of a prototype high oil hybrid. Transgenic Res., 25: 477-489.

Food and Agriculture Organization/World Health Organization, 1967. Requirement of Vitamin A, Thiamine, Riboflavin and Niacin. FAO Food and Nutrition Series B. Rome.

Goswami R., Zunjare R. U., Khan S., Baveja A., Muthusamy V., Hossain F., 2019. Marker-assisted introgression of rare allele of $\beta$-carotene hydroxylase ( $c r t R B 1$ ) gene into elite quality protein maize inbred for combining high lysine, tryptophan and provitamin $\mathrm{A}$ in maize. Plant Breed., 138:174-183. https://doi.org/10.1111/pbr.12676.

Goo Y. M., Han E. H., Jeong J. C., Kwak S. S., Yu J., Kim Y. H., Ahn M. J., Lee S. W., 2015. Overexpression of the sweet potato $\mathrm{IbOr}$ gene results in the increased accumulation of carotenoids and confers tolerance to environmental stresses in transgenic potato. Comptes Rendus Biologies, 338(1): 12-20

Halilu A. D., Ado S. G., Aba D. A., Usman I. S., 2016. Genetics of carotenoids for provitamin A biofortification in tropicaladapted maize. The Crop J., 4(4): 313-322.

Harjes C. E., Rocheford T. R., Bai L., Brutnell T. P., Kandianis C. B., Sowinski S. G., Buckler E. S., 2008. Natural genetic variation in lycopene epsilon cyclase tapped for maize biofortification. Science, 319: 330-333.

Howitt C. A., Pogson B. J., 2006. Carotenoid accumulation and function in seeds and non-green tissues. Plant Cell Environ., 29: 435-445.

Huang Z., Liu Y., Qi G., Brand D., Zheng S.G., 2018. Role of vitamin A in the immune system. J. Clin. Med., 7(9): 258

Institute of Medicine (US) Panel on Micronutrients, 2001. Dietary Reference Intakes for Vitamin A, Vitamin K, Arsenic, Boron, Chromium, Copper, Iodine, Iron, Manganese, Molybdenum, Nickel, Silicon, Vanadium and Zinc. (free download): National Academy Press. https:// doi.org/10.17226/10026. ISBN 978-0-309-07279-3. PMID 25057538.

Kim S. H., Ahn Y. O., Ahn M. J., Jeong J. C., Lee H. S. S., Kwak S. S., 2013. Cloning and characterization of an Orange gene that increases carotenoid accumulation and salt stress tolerance in transgenic sweet potato cultures. Plant Physiol. Biochemist., 70: 445-454.

Kurilich A. C., Juvik J. A., 1999. Quantification of carotenoid and tocopherol antioxidants in Zea mays. J. Agric. Food. Chem., 47: 1948-55.

Li L., Yang Y., Xu Q., Owsiany K., Welsch R., Chitchumroonchokchai C., Lu S., Van Eck J., Deng X. X., Failla M., Thannhauser T. W., 2012. The $\mathrm{Or}$ gene enhances carotenoid accumulation and stability during post-harvest storage of potato tubers. Mol. Plant., 5(2): 339-352. 
Li Z. H., Matthews P. D., Burr B., Wurtzel E. T., 1996. Cloning and characterization of a maize cDNA encoding phytoene desaturase, an enzyme of the carotenoid biosynthetic pathway. Plant Mol. Biol., 30: 269-279.

Lopez A. B., Van Eck J., Conlin B. J., Paolillo D. J., O'Neill J., Li L., 2008. Effect of the cauliflower $\mathrm{Or}$ transgene on carotenoid accumulation and chromoplast formation in transgenic potato tubers. J. Exp. Bot., 59 (2): 213-223.

Lu S., Eck Van J., Zhou X., Lopez A. B., O'Halloran D. M., Cosman K. M., Conlin B. J., Paolillo D. J., Garvin D. F., Vrebalov J., Kochian L. V., Kupper H., Earle E. D., Cao J., Li L., 2006. The cauliflower $O r$ gene encodes a DnaJ cysteine-rich domain containing protein that mediates high levels of beta-carotene accumulation. Plant Cell, 18: 3594-3605.

Matthews P. D., Wurtzel E. T., 2007. Food colorants: Chemical and functional properties. Boca Raton, FL: CRC. pp: 347-398.

Menkir A., Palacios-Rojas N., Alamu O., Dias Paes M. C., Dhliwayo T., Maziya-Dixon B., Mengesha W., Ndhlela T., Oliveira Guimarães PE., Pixley K., Torbert R., 2018. Vitamin A-Biofortifed Maize: Exploiting Native Genetic Variation for Nutrient Enrichment. Science Brief: Biofortifcation No. 2 (February 2018). CIMMYT, IITA, EMBRAPA, HarvestPlus, and Crop Trust. Bonn, Germany.

Messias R. S., Galli V., dos Anjos e Silva S. D., Rombaldi C. V., 2014. Carotenoid biosynthetic and catabolic pathways: Gene expression and carotenoid content in grains of maize landraces. Nutrients, 6: 546-563

Meyers K. J., Mares J. A., Igo R. P., Truitt B., Liu Z., Millen A. E., Klein M., Johnson E. J., Engelman C. D., Karki C. K., Blodi B., Gehrs K., Tinker L., Wallace R., Robinson J., LeBlanc E. S., Sarto G., Bernstein P. S., SanGiovanni J.
P., Iyengar S. K., 2014. Genetic evidence for role of carotenoids in age-related macular degeneration in the carotenoids in age-related eye disease study (CAREDS). Invest Ophthalmol Vis Sci., 55(1): 587-599.

Muzhingi T., Yeum K. J., Rusell R. M., Johnson E., Qin J., Tang G., 2008. Determination of carotenoids in yellow maize, the effect of saponification and food preparation. Int. J. Vitam. Nutr. Res., 78(3): 112-120.

Muthusamy V., Hossain F., Thirunavukkarasu N., Choudhary M., Saha S., Bhat J. S., Prasanna B.M., Gupta H.S., 2014. Development of $\beta$-Carotene rich maize hybrids through marker-assisted introgression of $\beta$-carotene hydroxylase allele. PLoS ONE, 9(12): e113583. https:// doi.org/10.1371/ journal.pone. 0113583.

Muthusamy V, Hossain F., Thirunavukkarasu N., Saha S., Agrawal P. K., Guleria S. K., Gupta H. S., 2015a. Genetic variability and inter-relationship of kernel carotenoids among indigenous and exotic Maize (Zea mays L.) Inbreds. Cereal Research Communications https:// doi.org/10.1556/0806.43.2015.012

Muthusamy V., Hossain F., Thirunavukkarasu N., Saha S., Gupta H.S., 2015b. Allelic variations for lycopene-e-cyclase and $\beta$ carotene hydroxylase genes in maize inbred and their utilization in $\beta$-carotene enrichment programme. Cogent Food \& Agriculture, 1: 1033141.

National Institute of Health. Office of dietary supplements fact sheet: Vitamin A.

Naqvi S., Zhu C., Farre G., Ramessar K., Bassie L., Breitenbach J., Perez Conesa D., Ros G., Sandmann G., Capell T., Christou P., 2009. Transgenic multivitamin maize through biofortification of endosperm with three vitamins representing three distinct metabolic pathways. Proc. Natl. Acad. Sci., USA, 106: 7762-7767. 
Neilson J. A., Durnford D. G., 2010. Evolutionary distribution of lightharvesting complex-like proteins in photosynthetic eukaryotes. Genome, 53: 68-78.

Ortiz-Monasterio J. I., Palacios-Rojas N., Meng E., Pixley K., Trethowan R., Penaet R. J., 2007. Enhancing the mineral and vitamin content of wheat and maize through plant breeding. J. Cereal. Sci., 35 (46): 293-307.

Park S. C., Kim S.H., Park S., Lee H. U., Lee J. S., Park W. S., Ahn M. J., Kim Y. H., Jeong J. C., Lee H. S., Kwak S. S., 2015. Enhanced accumulation of carotenoids in sweetpotato plants overexpressing $\mathrm{IbOr}$ Ins gene in purple-fleshed sweetpotato cultivar. Plant Physiol. Biochem., 86: 82-90.

Paul J. Y., Khanna H., Kleidon J., Hoang P., Geijskes J., Daniells J., Zaplin E., Rosenberg Y., James A., Mlalazi B., Deo P., Arinaitwwe G., Namanya P., Becker D., Tindamanyire J., Tushemereirwe W., Harding R., Dale J., 2017. Golden bananas in the field: elevated fruit pro-vitamin A from the expression of a single banana transgene. Plant Biotechnol. J., https:// doi.org//10.1111/pbi.12650.

Pixley K., Palacios N., Babu R., Mutale R., Surles R., Simpungwe E., 2013. Biofortifcation of maize with provitamin a carotenoids. In: Carotenoids and Human Health. Tanumihardjo, Sherry A. (Ed.) Humana Press. Chapter 17: 271-292.

Pons E., Alquezar B., Rodriguez A., Martorell P., Genoves S., Ramon D., Rodrigo M.J., Zacarias L., Pena L., 2014. Metabolic engineering of beta-carotene in orange fruit increases its in vivo antioxidant properties. Plant Biotechnol. J., 12: 17-27.

Sagare D. B., Shetti P., Surender M., Reddy S. S., 2019. Marker-assisted backcross breeding for enhancing $\beta$-carotene of QPM inbred. Mol. Breed., 31. https:// doi.org/10.1007/s11032-019-0939-x.
Seo M., Koshiba T., 2002. Complex regulation of ABA biosynthesis in plants. Trends Plant Sci., 7(1): 41-48.

Suwarno W.B., Pixley K.V., Palacios-Rojas N., Kaeppler S.M., Babu R., 2014. Formation of heterotic groups and understanding genetic effects in a provitamin A biofortified maize breeding program. Crop. Sci., 54: 14. https:// doi.org/10.2135/cropsci2013.02.0096.

Romer S., Lubeck J., Kauder F., Steiger S., Adomat C., Sandmann G., 2002. Genetic engineering of a zeaxanthin-rich potato by antisense inactivation and co-suppression of carotenoid epoxidation. Metab Eng., 4: 263-272.

Ross D. A., 1998. Vitamin A and public health: Challenges for the next decade. Proc. Nutrition. Society, 57: 159-165.

Semba R. D., 1994. Vitamin A, immunity, and infection. Clin. Infect. Dis.. 19(3): 489-499.

Semba R. D., 2009. The role of vitamin A and related retinoid in immune function. Nutrition Review, 56(1): s38-s48.

Seo M., Koshiba T., 2002. Complex regulation of ABA biosynthesis in plants. Trends in Plant Sci., 7: 41-48.

Tang G., 2010. Bioconversion of dietary provitamin A carotenoids to vitamin A in humans. Am. J. Clin. Nutr., 91(suppl): $1468 \mathrm{~S}-73 \mathrm{~S}$.

Thirusendura Selvi D., Senthil N., Yuvaraj A., John Joel A., Mahalingam A., Nagarajan P., Vellaikumar S., Srimathi P., Raveendran M., Nepolean T., 2014. Assessment of crtRB1 polymorphism associated with increased $\beta$-carotene content in maize (Zea mays L.) Seeds. Food Biotechnol., 28(1): 41-49.

Tran T. L., Ho T. H., Nguyen D. T., 2017. Overexpression of the $\mathrm{IbOr}$ gene from sweet potato (Ipomea batatas 'Hoang Long') in maize increases total carotenoid and $\beta$-carotene contents. Turk. J. Biol., 41: 1003-1010. 
Tzuri G., Zhou X., Chayut N., Yuan H., Portnoy V., Meir A., Sa'ar U., Baumkoler F., Mazourek M., Lewinsohn E., Fei Z., Schaffer A. A., Li L., Burger J., Katzir N., Tadmor Y., 2015. A 'golden' SNP in $\mathrm{CmOr}$ governs the fruit flesh color of melon (Cucumis melo). Plant J., 82: 267-279.

United States Institute of Medicine, 2001. Dietary reference intakes for vitamin A, vitamin $\mathrm{K}$, arsenic, boron, chromium, copper, iodine, iron, manganese, molybdenum, nickel, silicon, vanadium and zinc. Washington, DC: National Academy Press.

US National Institutes of Health, 2016. Vitamin A. MedlinePlus, National Library of Medicine.

Vallabhaneni R., Wurtzel E. T., 2009. Timing and biosynthetic potential for carotenoid accumulation in genetically diverse germplasm of maize. Plant Physiol., 150: 562-572.

Vignesh M., Hossain F., Nepolean T., Saha S., Agrawal P. K., Guleria S. K., Prasanna B. M., Gupta H. S., 2012. Genetic variability for kernel $\beta$-carotene and utilization of crtRBI 3'TE gene for biofortification in maize (Zea mays L.). Indian J. Genet., 72: 189-194.

Vishnevetsky M., Ovadis M., Vainstein A., 1999. Carotenoid sequestration in plants: the role of carotenoid-associated proteins. Trends Plant Sci., 4: 232-235.

Wang C., Zeng J., Li Y., Hu W., Chen L., Miao Y., Deng P., Yuan C., Ma C., Chen X., Zang M., Wang Q., Li K., Chang J., Wang Y., Yang G., He G., 2014. Enrichment of provitamin A content in wheat (Triticum aestivum L.) by introduction of the bacterial carotenoid biosynthetic genes $C r t B$ and CrtI. J. Exp. Bot., 65: 2545-2556.

Wang Z., Ke Q., Kim M. D., Kim S. H., Ji C. Y., Jeong J. C., Lee H. S., Park W. S., Ahn M. J., Li H., Xu B., Deng X., Lee S. H., Lim Y. P., Kwak S. S., 2015.
Transgenic alfalfa plants expressing the sweetpotato Orange gene exhibit enhanced abiotic stress tolerance. PLoS ONE, 10: e0126050.

Welsch R., Arango J., Bar C., Salazar B., AlBabili S., Beltran J., Chavarriaga P., Ceballos H., Tohme J., Beyer P., 2010. Provitamin A accumulation in cassava (Manihot esculenta) roots driven by a single nucleotide polymorphism in a phytoene synthase gene. Plant Cell, 22: 3348-3356.

World Health Organization, 2010. World health statistics. Geneva, Switzerland: WHO.

Wurtzel T. E., Cuttriss A., Vallabhaneni R., 2012. Maize provitamin A carotenoids, current resources, and future metabolic engineering challenges. Fronties in Plant Sci., 3: 1-12. https:// doi.org/ 0.3389/fpls.2012.00029.

Yan J. B., Kandianis C. B., Harjes C. E., Bai L., Kim E. H., Yang X. H., Skinner D. J., Fu Z. Y., Mitchell S., Li Q., Salas Fernandez M. G., Zaharieva M., Babu R., $\mathrm{Fu}$ Y., Palacios N., Li J. S., DellaPenna D., Brutnell T., Buckler E. S., Warburton M. L., Rocheford T., 2010. Rare genetic variation at Zea mays crtRB1 increases bcarotene in maize grain. Nature Genetics, 42: 322-327.

Ye X., Al-Babili S., Kloti A., Zhang J., Lucca P., Beyer P., Potrykus I., 2000. Engineering the provitamin A (betacarotene) biosynthetic pathway into (carotenoid-free) rice endosperm. Science, 287: 303-305.

Zanga D., Capell T., Slafer G. A., Christou P., Savin R., 2016. A carotenogenic mini pathway introduced into white maize does not affect development or agronomic performance. Scientific Reports, 6: 1-12

Zeng J., Wang X., Miao Y., Wang C., Zang M., Chen X., Li M., Li X., Wang Q., Li K., Chang J., Wang Y., Yang G., He G. 
2015. Metabolic engineering of wheat provitamin A by simultaneously overexpressing $C r t B$ and silencing carotenoid hydroxylase (TaHyd). J. Agric. Food. Chem., 63: 9083-9092.

Zhu C. F., Naqvi S., Breitenbach J., Sandmann G., Christou P., Capell T., 2008. Combinatorial genetic transformation generates a library of metabolic phenotypes for the carotenoid pathway in maize. Proc. Nat. Acad. Sci. USA, 105: 18232-18237.

Zhou X., Van Eck J., Li L., 2008. Use of the cauliflower $O r$ gene for improving crop nutritional quality. Biotech. Ann. Rev., 14: 171-190.
Zhou X., Welsch R., Yanga Y., Álvarez D., Riediger M., Yuana H., Fish T., Liu J., Thannhauser T.W., Li L., 2015. Arabidopsis OR proteins are the major posttranscriptional regulators of phytoene synthase in controlling carotenoid biosynthesis. Proc. Nat. Acad. Sci. USA, 12(11): 3558-3563.

Zunjare R. U., Hossain F., Muthusamy V., Baveja A., Chauhan H. S., Bhat J. S., Thirunavukkarasu N., Saha S., Gupta H. S., 2018. Development of biofortified maize hybrids through marker-assisted stacking of $\beta$-carotene hydroxylase, lycopene-e-cyclase and Opaque2 genes. Front Plant Sci., 9: 178. https:// doi.org/10.3389/fpls.2018.00178. 